Musées, Patrimoine et Culture scientifiques et techniques

$111 \mid 2007$

mai - juin 2007

\title{
Le prix des choses sans prix
}

\section{Serge Chaumier}

URL : http://journals.openedition.org/ocim/756

DOI : $10.4000 /$ ocim.756

ISSN : 2108-646X

Éditeur

OCIM

Édition imprimée

Date de publication : 1 mai 2007

Pagination : 4-7

ISSN : 0994-1908

Référence électronique

Serge Chaumier, "Le prix des choses sans prix », La Lettre de I'OCIM [En ligne], 111 | 2007, mis en ligne le 15 mars 2011, consulté le 19 avril 2019. URL : http://journals.openedition.org/ocim/756 ; DOI :

10.4000/ocim.756

Tous droits réservés 


\section{Le prix des choses sans prix}

\section{Serge Chaumier *}

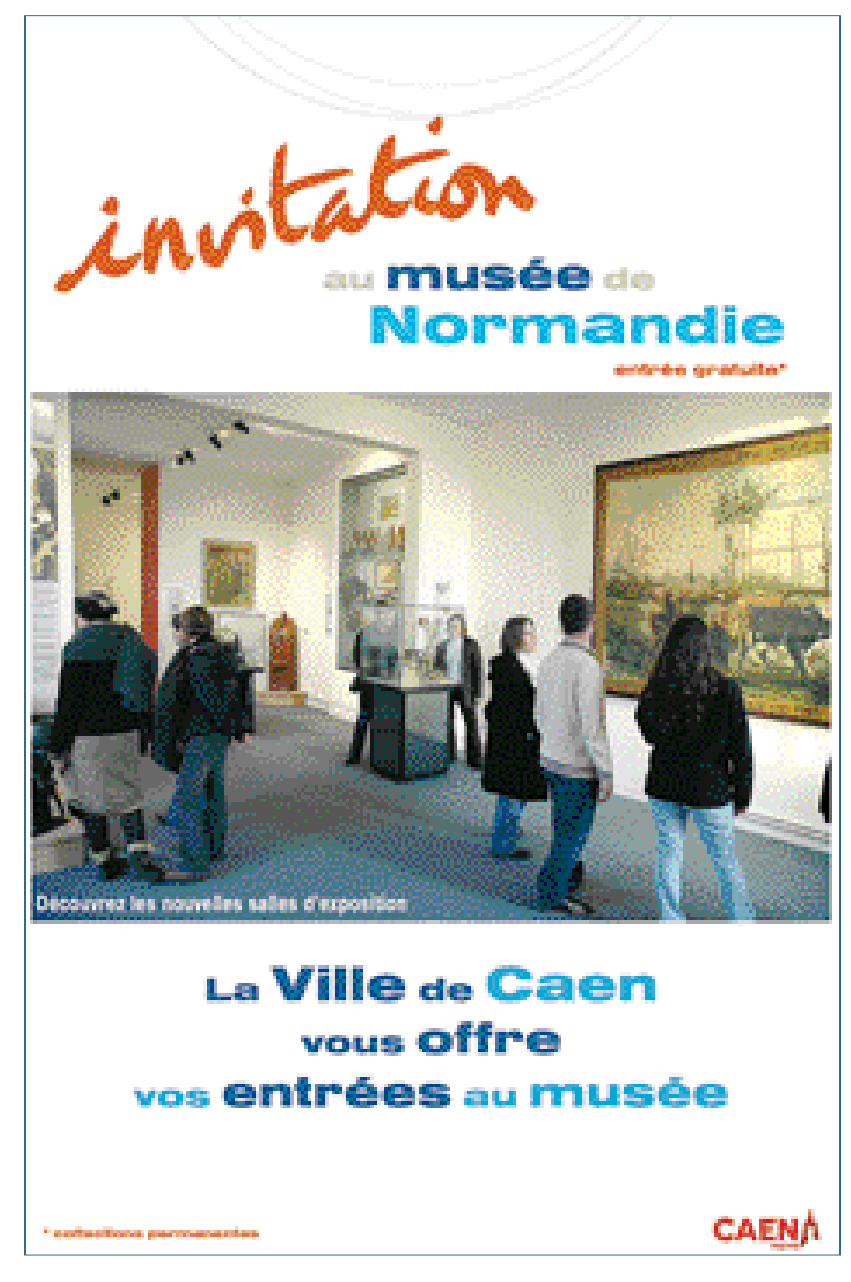

() Ville de Caen

* Serge Chaumier est professeur à l'IUP Denis Diderot, Centre de Recherche sur la Culture et les Musées de l'université de Bourgogne serge.chaumier@u-bourgogne.fr

\begin{abstract}
"Lorsque la conscience d'un droit arrive à maturité, qu'elle se répand dans la société, que toute atteinte à ce droit provoque un sentiment de révolte, quand l'ordre établi ne parvient plus à imposer sa représentation des choses et ne récompense plus la soumission des esprits par le relatif confort mental qu'on trouve à se satisfaire de la normalité, la gratuité est lavée du soupçon de douce utopie et peut se transmuter en objectif mobilisateur ».
\end{abstract}

Jean-Louis Sagot-Duvauroux, De la Gratuité, L'Éclat Paris, 2006.

Par cette formule de Marcel Mauss, qui s'applique à merveille à l'univers des musées, et qu'affectionnait particulièrement Jean Duvignaud, il s'agit de signifier l'essence des choses ${ }^{(1)}$. Bien inaliénable, patrimoine de l'humanité, ce qui entre au musée sort du cycle des biens marchands, de la consommation et même des processus de l'échange, et pour cela n'a plus de prix. Ce n'est pas pour rien que les métaphores du sacré sont attachées à l'univers muséal. C'est aussi pour cette raison que l'idée d'une possible location des œuvres dont l'institution est dépositaire (et non propriétaire), agit comme un spectre qui réveille les passions. Le musée appartient à tous, car il est bien collectif de la Nation tout entière symbolisée par ce bien commun. Dès lors comment en faire payer l'entrée, comment en fixer le prix ? Même si il ne subsiste qu'une représentation collective, pour ne pas dire un fantasme, de cette idée révolutionnaire, l'imaginaire continue de fonctionner et explique que les débats autour de la gratuité des musées soient si récurrents et si virulents. Après tout qui s'inquiète de la gratuité des théâtres ? 
La question n'est cependant pas incongrue. Rappelons ce rêve d'André Malraux : «il faut bien admettre qu'un jour on aura fait pour la culture ce que Jules Ferry a fait pour linstruction : la culture sera gratuite » (2). Si « la culture doit être tôt ou tard gratuite », pour le ministre qui prononce ces mots en inaugurant la maison de la Culture de Grenoble, c'est justement que ces nouvelles cathédrales doivent prolonger le travail d'un Jean Vilar au Théâtre National Populaire, rassembler la Nation en proposant de l'élever. Comme l'instruction hier, la culture a pour mission, elle, non d'éduquer, mais d'apporter du sens, c'est-àdire d'élever l'âme de chacun. C'est ce partage d'une communauté ressaisie et tendue vers l'affirmation d'elle-même dans ce qu'elle a de meilleure qui soustend la logique de la gratuité. Car il ne peut y avoir de collectivité rassemblée dans une logique de séparation aristocratique. Nécessairement la générosité implique la démocratie, et réciproquement.

Le lecteur pourra estimer que l'on est bien loin avec ces réflexions du débat contemporain sur le droit d'entrée dans les musées. Et pourtant, n'est-ce pas ce qui se joue dans la réintroduction du principe de gratuité dans un certain nombre d'établissements (à Paris, Dijon, Bordeaux, Caen, en Isère...), alors que l'on aurait pu croire il y a une dizaine d'années encore que cette tendance était définitivement reléguée aux prémisses de l'histoire muséale? La réaffirmation de la gratuité ne sonne t-elle pas comme une volonté de marquer la différence entre les lieux de culture et les lieux de loisirs ? Parce que la culture ne consiste pas à gonfler les propositions du divertissement, mais qu'elle a d'autres missions plus essentielles? Il s'agit peut-être inconsciemment de souligner la distinction entre une évolution commerciale qui semble menacer de toute part et une résistance de la culture à incarner d'autres valeurs ${ }^{(3)}$. Car malgré ce que l'on voudrait nous faire croire, la culture n'a rien à voir avec l'univers de la marchandise, de ses produits et de ses cibles de clientèle ${ }^{(4)}$. C'est pour cette raison, que l'on est (encore) si attaché au principe de gratuité ou de moindre coût dans les bibliothèques.

Dès lors les spécialistes du marketing peuvent bien nous prouver que la grande partie des visiteurs serait prête à payer un droit d'entrée, et même un droit élevé, peu importe. Ce qui compte c'est cette partie même minime pour laquelle est affirmée une solidarité, c'est la portée du geste. Car la Nation ne se nourrit pas de chiffres et de statistiques, mais de symboles. C'est même là où le politique peut assumer des choix, sans nécessairement se plier aux dictats de l'économie. On ne gouverne pas à coups d'expertise, mais selon une vision de l'avenir. Affirmer le principe de gratuité, ou un prix d'entrée symbolique, comme c'était le cas dans beaucoup de lieux, il y a encore peu de temps, c'est signifier au visiteur quelque chose de différent que de lui demander de consentir à un effort lourd. La sémiologie doit s'inviter dans un débat que l'on ne doit pas abandonner aux seuls économistes. C'est le sens de cette protestation si souvent entendue chez des visiteurs qui font remarquer que les impôts existent pour ça.

Selon deux approches différentes, mais complémentaires, Claude Fourteau et François Mairesse reviennent dans leurs contributions sur le principe du don. Le don appelle le contre-don, pas mécaniquement, mais métaphoriquement. Parce que tu me donnes, je donne à autrui. La réciprocité est avant tout imaginaire, même si l'échange qui contribue à fortifier le corps social est, lui, bien réel. À l'opposé d'une logique de consommation, qui induit que l'on est quitte une fois son écot déposé, le don engage et crée un lien. Les musées et les monuments devraient sous-peser cette donnée avant que d'instituer un lourd tribut. Car inviter gratuitement, c'est provoquer de l'attachement, là où faire payer est affirmer un désinvestissement. Qu'on le veuille ou non le don est lié à l'amour, et réciproquement. Si on veut que le public se sente responsable d'un patrimoine commun, et redevable de sa préservation, c'est peut-être en lui offrant qu'on le liera durablement à lui. Ceci n'engage pas seulement le respect et la reconnaissance dans le court terme, l'esquive d'une attitude de consommateur, c'est construire un sentiment commun d'engagement et d'appartenance. Même si c'est finalement « une filiation inversée ", car désigné par celui qui en hérite ${ }^{(5)}$, le patrimoine, c'est ce que j’ai l'impression de recevoir malgré

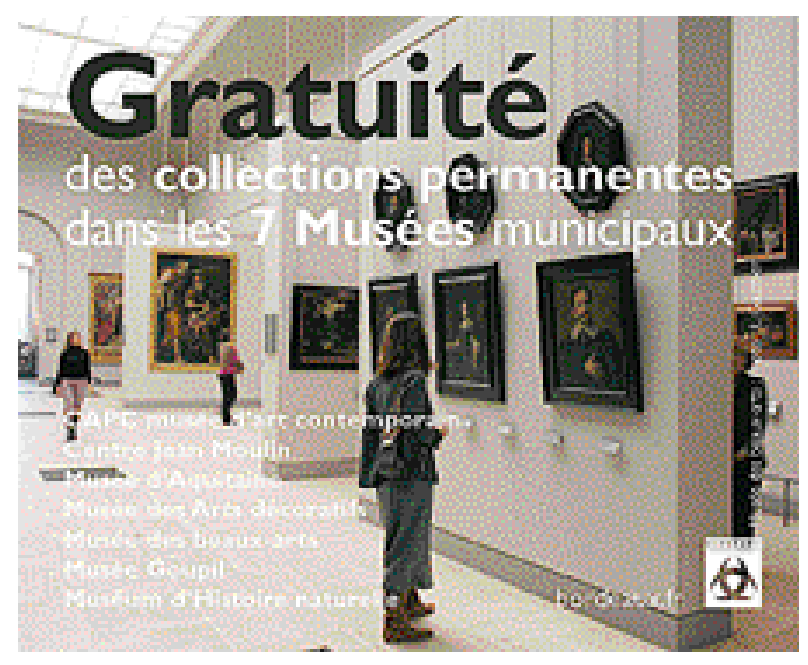

() Ville de Bordeaux 
moi et envers lequel je me sens par conséquent obligé. Les musées anglais l’ont bien compris qui invitent gratuitement à donner pour entrer...

Évidemment les cartes sont souvent brouillées et en deviennent illisibles, car si la tendance est d'un côté à la hausse des prix pour les « offres culturelles » (sic) (6), le système marchand tend, lui, à faire croire à l'avènement du gratuit. « $20 \%$ de produit en plus » et abonnement téléphonique sans bourse délier : promotion et gratuité envahissent le marché, jusqu'aux journaux gratuits, et cette valorisation - dévalorisation du gratuit est évidemment un trompe-l'œil d'une nouvelle forme du capitalisme financé par la publicité. Mais la confusion n'est pas innocente, car cela promeut un inversement des valeurs, ce qui était gratuit parce que relevant du service public devrait devenir payant (comme l'école...), et ce qui était jusque-là payant se promeut comme gratuit. Cependant lorsque une réelle gratuité menace de s'installer au cœur du système, avec Internet par exemple et le peer to peer, alors c'est l'affolement du côté des industries culturelles ${ }^{(7)}$. Le cauchemar «d'un ennemi redoutable : le rêve de la gratuité », saisit même le ministre de la Culture ${ }^{(8)}$. Il devient par conséquent difficile de s'y retrouver. Si chaque secteur à ses caractéristiques propres et ses logiques internes, il n'empêche que le débat sur la gratuité dans les musées s'insère dans un contexte social plus large que l'on ne peut méconnaître. La question concerne également par exemple les arts de la rue, ou les fêtes culturelles comme Nuit blanche, Lille $2004 \ldots$ L'affirmation de la gratuité est symbole d'accessibilité et de partage, d'un tous ensemble.

Il est certes des discours pour prétendre que ce que l'on ne paye pas serait considéré comme sans valeur (et cela sonne bizarrement si on maintient le lien entre la gratuité, le don et l'aimer...). C'est, rappelle JeanLouis Sagot-Duvauroux, l'argument qui était employé par la presse catholique pour s'opposer à la gratuité de l'école lors de sa mise en place par peur que l'instruction facilement acquise ne perde de son prix, et que les enfants oublient "la gratitude salutaire envers leurs parents si ceux-ci ne sont pas contraints de se sacrifier pour les envoyer à l'école» (9). Opposition étonnante (et Claude Fourteau a repéré et analysé les multiples formes de résistance aux mesures en faveur de la gratuité), qui est relayée de nos jours par un argumentaire aux allures plus modernes. La gratuité bénéficierait surtout à ceux qui profiteraient ainsi de « l'effet d'aubaine », entrant gratuitement alors qu'ils étaient prêts à débourser. L'idée a pour effet de minimiser ainsi la part non négligeable de ceux qui, même minoritaires dans la statistique, constituent néanmoins des milliers de personnes réelles qui viennent et reviennent, accompagnent et découvrent, alors qu'elles se seraient sans cela abstenues. Il ne faut pas oublier que la gratuité modifie profondément les types et pratiques de visites, permettant à des publics novices d'adopter des attitudes habituellement réservées aux publics familiers des institutions, comme de venir pour peu de temps, pour une chose précise, pour accompagner quelqu'un, ou pour effectuer une visite de reconnaissance. Ces profils de visiteurs se dévoilent au fil des pages de l'enquête qualitative réalisée par l'équipe dirigée par Anne Gombault et Christine Petr.

D'autres arguments prétendent que l'on finance ainsi collectivement ceux dont la pratique est déjà acquise et qui devraient plutôt contribuer directement à leurs passions. La philosophie de l'utilisateur payeur revient en scène. Négation même du collectif, et privatisation des politiques publiques, la transformation de l'usager citoyen en consommateur, s'inscrit dans une individualisation des pratiques et une vision tronquée d'un libre choix souverain. Comme si seules les personnes qui sortent la nuit devaient contribuer à l'éclairage public. Ici encore le principe de solidarité et de fraternité, bref d'unité, est en question, valeurs intrinsèquement inscrites dans le principe de gratuité que Jean-Louis Sagot-Duvauroux remémore. C'est justement le caractère de financement collectif qui plaide pour la mise en œuvre inlassable des processus de démocratisation, et non son relatif échec qui doit servir d'arguties à la privatisation des biens collectifs. C'est parce que la collectivité tout entière est impliquée que l'on peut définir et défendre le bien commun.

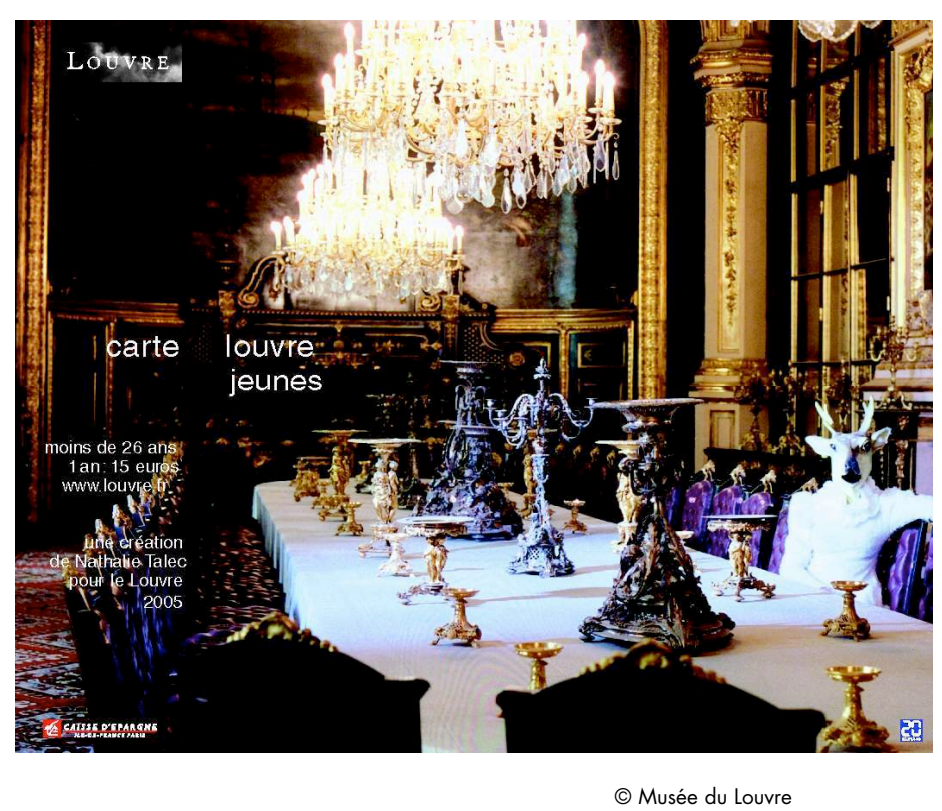


Que Ségolène Royal comme Nicolas Sarkozy aient proposé d'inscrire comme mesure politique la gratuité d'entrée dans les musées nationaux est symptomatique ${ }^{(10)}$. Certes, "la gratuité n'est pas seulement une mesure politique. Elle ne subsiste, ne naît et ne prospère qu'entourée des valeurs qui la font chérir et désirer », écrit Sagot-Duvauroux. À ce titre, le peu de discours d'accompagnement des mesures annoncées par les politiques, au niveau national comme au niveau des collectivités territoriales, comme le mentionne Philippe Mathieu, peut laisser dubitatif. Car la gratuité n'est rien si elle ne s'insère pas dans une véritable réflexion d'ensemble sur les politiques tarifaires. Sans doute, la gratuité a plus de force si elle est accompagnée, si elle est intermittente, ou si on lui donne un caractère solennel. Ainsi délivrer des tickets gratuits et laisser le passage libre, n'a pas la même signification, le premier cas insiste sur la faveur accordée et sensibilise, là où le second cas banalise. De même, une vraie mesure d'accessibilité et de démocratisation ne serait-elle pas d'accorder par exemple en priorité la gratuité à certaines catégories de public, par exemple aux personnes nonimposables ? Une façon de "laissez rêver les pauvres », pour reprendre la superbe expression de Georges Clemenceau s'opposant au Louvre payant à la fin du XIX ${ }^{e}$ siècle (11). Un accord entre le ministère de la Culture et celui des Finances pour délivrer une carte spécifique aurait pour effet d'insister sur un «privilège » et peut-être de mieux inciter à en profiter. Sans compter qu'une telle carte est susceptible d'avoir un effet d'entrainement sur d'autres collectivités, et pour l'accès à d'autres offres culturelles. De plus, la visite des expositions n'est pas tout, et la meilleure accessibilité par exemple aux médiations pourrait être également efficacement modulée.

Il est devenu discriminatoire et normalement illégal par le droit européen de donner une préférence territoriale aux visiteurs, ainsi d'accorder la gratuité aux locaux. Pourtant, il est indéniable que la question de la tarification se pose avec la montée en puissance du tourisme. Comme l'a analysé François Mairesse, c'est la manne des flux touristiques qui conduit à envisager et développer la tarification. Du reste, les pays peu touristiques sont beaucoup moins portés à des niveaux de prix élevés. Il est légitime de se demander si un touriste qui a les moyens de se déplacer et de s'offrir un hébergement de vacances doit se voir invité gratuitement au musée. Il est sans doute plus productif d'inventer des mesures adaptées, comme de permettre un retour illimité avec le même billet aux résidents de proximité, qui deviendront ainsi des ambassadeurs privilégiés du lieu, plutôt que de mettre en place une mesure indistincte de gratuité pour tous. Il n'y a sans doute pas de solution unique, et toute réponse univoque et doctrinaire doit être évitée, chaque établissement avec sa spécificité et son histoire, doit inventer des solutions adaptées (12). Les passeports et billets couplés, comme le présente ici Cathy Savioz pour la Suisse, sont également des pistes possibles à explorer. Ce numéro thématique de la Lettre de l'OCIM a pour objectif de nourrir un débat qui est souvent passionné, parce qu'il touche aux fondamentaux de l'action culturelle. Espérons qu'il puisse contribuer, à sa juste mesure, au dialogue.

\section{Notes}

(1) Duvignaud, J. Le Prix des choses sans prix. Actes Sud, 2001.

(2) Discours à l'Assemblée nationale le 9 novembre 1967 et Discours d'inauguration de la maison de la Culture de Grenoble le 13 février 1968, in André Malraux, Ministre. La Documentation française, 1996.

(3) Voir le $n^{\circ} 5$ de Culture \& Musées, Du musée au parc d'attractions, sous la direction de Serge Chaumier, 2005.

(4) Sur ce sujet voir Chaumier, S. Parce que la culture n'est pas une marchandise..., Cassandre, $\mathrm{n}^{\circ} 69$, mai 2007.

(5) Selon la démonstration Davallon, J. Le Don du patrimoine. Hermès, 2006. (6) Rouet, F. Le retour de la question tarifaire, in Les Tarifs de la culture. La Documentation française, 2002, p. 15.

(7) Olivennes, D. La gratuité, c'est le vol. Quand le piratage tue la culture. Grasset, 2007.

(8) Renaud Donnedieu de Vabres à l'occasion du débat sur la loi sur le Droit d'auteur et les droits voisins dans la société de linformation, cité par SagotDuvauroux, J.-L. Vive la gratuité !, Le Monde Diplomatique, juillet 2006, p. 28. (9) Sagot-Duvauroux, J.-L. De la Gratuité, L'Éclat, Paris, 2006.

(10) Lesprit, B. et De Roux E. Culture gratuite, gratuité de la culture, Le Monde, 8 décembre 2006.

(11) Samsoen, D. Petite histoire de la gratuité dans les musées nationaux, in Les tarifs de la culture. La Documentation française, 2002, p. 284.

(12) On pourra lire des formules différentes et une réflexion pour le spectacle vivant dans Soigner sa politique tarifaire, La Scène, nº43, décembre 2006.

\section{Bibliographie}

Fourteau, C. (dir.) Les Institutions culturelles au plus près du public. Conférences et colloques du Louvre, La Documentation française.

Fourteau, C., Le premier dimanche du mois au musée du Louvre, ce qui n'a pas de prix est gratuit, La Gratuité du dimanche au Lowvre, rapport d'évaluation 1996-2000, musée du Louvre, 2002.

Gombault, A., Petr, C., Bourgeon-Renault, D., Le Gall-Ely M. et Urbain, C. La Gratuité des musées et des monuments côté publics. La Documentation française, 2007.

Mairesse, F. Le Droit d'entrer au musée. Éditions Labor, 2005.

Mairesse, F. La stratégie du prix, Publics $\&$ Culture, n¹1-12, 1997, pp. 141-162.

Rouet, F. (dir.) Les tarifs de la culture. La Documentation française, 2002.

Sagot-Duvauroux, J.-L. De la Gratuité, L'Éclat, Paris, 2006 (téléchargeable sur www.lyber-eclat.net/lyber/sagotl/gratuite.html) 